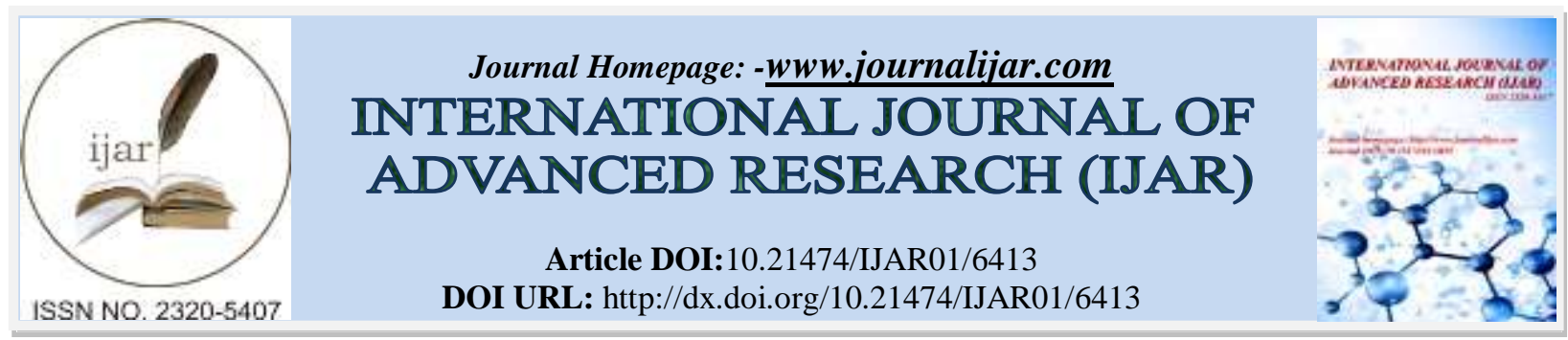

RESEARCH ARTICLE

\title{
STUDY AND COMPARISON OF KNOWLEDGE OF MEDICAL STUDENTS AND INTERNS ABOUT PHARMACOTHERAPEUTICS.
}

Dr. Meghna Pandey, ${ }^{1}$ Dr. Poonam Salwan ${ }^{2}$, Dr. Juhi Singla ${ }^{3}$, Dr. Shalini Salwan ${ }^{4}$ and Dr. Shalini Ray ${ }^{5}$

1. Assistant Professor, Department of pharmacology, SGT Medical College and Hospital, Budhera, Gurgaon.

2. Associate Professor, Department of pharmacology, SGT Medical College and Hospital, Budhera, Gurgaon.

3. PG Student, Department of pharmacology, SGT Medical College and Hospital, Budhera, Gurgaon.

4. Professor, Department of pharmacology, Punjab Institute of Medical Sciences, Garha Road, Jalandhar.

5. Assistant Professor, Department of Community Medicine, SGT Medical College and Hospital, Budhera, Gurgaon.

\section{Manuscript Info}

Manuscript History

Received: 02 December 2017

Final Accepted: 04 January 2018

Published: February 2018

Key words:-

education, integrated teaching, medical student, undergraduate.
Abstract

Aim: Pharmacotherapy might be improved if MBBS students receive an integrated educational programme in pharmacology and pharmacotherapeutics. This study investigated whether there are differences in the pharmacology and pharmacotherapy knowledge between medical students and interns after their undergraduate training. Differences could serve as a starting point from which integrated educational programmes can be developed for better MBBS education.

Methods: In a cross-sectional design, the knowledge of medical students and interns were assessed, using a standardized test with four domains (Emergency conditions, cardiovascular pharmacology, analgesics and Chemotherapy).

Results: One hundred medical students and one hundred interns were included in the cross-sectional questionnaire based study. The response rate was $91.36 \%$ for MBBS and $98.16 \%$ for Interns. Interns had better knowledge of Cardivascular pharmacology than medical students (mean score of Interns 4.53 \pm 1.3; MBBS 2.35 \pm 1.2 ).In addition, data related to drugs used in emergency and chemotherapy showed much better knowledge of the interns (mean score of Interns $2.24 \pm 0.7$; \& MBBS $1.97 \pm 0.7$ ) and (mean score of Interns $4.12 \pm 1.05 \&$ MBBS $3.5 \pm$ 1.23) respectively. However, the two groups had almost similar knowledge of analgesic use and dosage (mean score of Interns $2.53 \pm$ $0.78 \&$ MBBS 2.41 \pm 0.93 ).

Conclusions: Interns have better knowledge of basic pharmacology and of the application of knowledge of pharmacology than medical students. Differences in knowledge and skills therefore might well stem from their undergraduate education. Knowledge of these differences could be harnessed to develop an integrated teaching programme for medical students.

Copy Right, IJAR, 2018,. All rights reserved. 


\section{Introduction:-}

Pharmacology forms one of the most important subjects in medical curriculum and can be considered as the backbone of Clinical Medicine. ${ }^{(1)}$ Prescribing the appropriate and rational therapy is the essential duty of doctors and hence, adequate knowledge about the drug's efficacy, safety, cost, and convenience is of utmost importance. ${ }^{(2)}$ Proper training in pharmacology can enhance medical students' knowledge and skill about drug prescription along with their utility in various diseases. ${ }^{(3)}$

Selection of the most appropriate drug, dosage and duration of treatment taking into account the specific features of a patient are a part of pharmacotherapeutics ${ }^{(4)}$.An integrated knowledge of pharmacotherapeutics along with good clinical exposure is vital in the formation of a good healthcare professional.Nowadays the approach of horizontal integration of pharmacology along with microbiology, pathology as well as vertical integration with medicine and surgery is applied to have a proper understanding of the subject. All this is done with the help of didactic lectures, audio-visual aids, tutorials \& computerized animal simulation experiments ${ }^{(5)}$.

This questionnaire based study was done to compare the knowledge of pharmacotherapeutics among $2^{\text {nd }}$ year MBBS undergraduates with that of Interns. The goal of this study was to investigate differences in pharmacology and pharmacotherapy knowledge of $2^{\text {nd }}$ year medical students and students after their undergraduate training and to find out whether exposure to clinical practice as Intern; can help to enhance the knowledge of pharmacotherapeutics.. Knowledge of potential differences can be used to develop integrated educational programmes, both undergraduate and postgraduate, with a view to improving interdepartmental collaboration and medical care.

\section{Material and Methods:-}

After obtaining due approval of the institutional Ethics Committee, a cross-sectional questionnaire based study was conducted amongst $2^{\text {nd }}$ professional MBBS exam going students and Interns of a private medical college in NCR. An exhaustive questionnaire of multiple choice questions related to common medical conditions was prepared. Questionnaires of similar studies were taken into consideration while framing questions for the current study ${ }^{(6-}$

${ }^{8)}$.Each question had four options out of which one was correct. Test questions were discussed and reviewed by senior faculty members of the department of pharmacology. Questions that were found to be inappropriate were either removed or altered. One mark was awarded for each correct response. Based on the number of correct responses, students were given marks. Total time of twenty five minutes was allotted to solve the questionnaire. The data was collected and tabulated in an anonymous fashion to avoid any conflicts and bias. Those who scored below 10 were graded as poor, $10-15$ as average, and 16-20 as good $\&$ above 21 as very good.

\section{Statistical Analysis:-}

Descriptive statistics was used for the evaluation of the data. The total score of MBBS and Interns was compared using student's unpaired t- test. Student performance was graded as poor, average, good \& very good on the basis of total score obtained and statistical significance of the difference was calculated by chi-square test. SPSS software was utilized in the statistical analysis of the data.

\section{Observations and Results:-}

For the study, we enrolled a total of 200 students ( $2^{\text {nd }}$ professional MBBS $n=100 \&$ Intern $\left.n=100\right)$. Total Mean score of MBBS students was found to be $9.43 \pm 3.38$ and for Interns it was $13.28 \pm 2.55$. The total score of MBBS and Interns was compared using student's t- test. Student performance was graded as poor, average, good \& very good on the basis of total score obtained and statistical significance of the difference was calculated by chi-square test. It was found that only $9 \%$ MBBS students while $29 \%$ Interns got the good grade. 10\% Interns got very good grade while only $1 \%$ MBBS student could manage to get the same. (Table1)(Fig.1)

Among the total students; the percentage of unattempted questions by MBBS students was 8.64\%, as compared to Intern students was $1.84 \%$ (Fig.2)

The difference in the mean correct score for Interns and MBBS students was found to be significant in the domains of CVS, chemotherapy and emergency conditions. However, in analgesics the difference in the mean correct score for Interns and MBBS students was not found to be significant (p value=0.36) (Table2) (Fig.3) 
Table 1:- Grading of percentage score among MBBS students and Interns

\begin{tabular}{|c|c|c|c|c|}
\hline Grade & Score & MBBS & Interns & p-value \\
\hline Poor & $<10$ & $43 \%$ & $08 \%$ & \multirow{4}{*}{$\begin{array}{l}\mathrm{X}^{2}=32.94 \\
<0.001 \\
\text { (Highly } \\
\text { significant) }\end{array}$} \\
\hline Average & $10-15$ & $52 \%$ & $82 \%$ & \\
\hline Good & $16-20$ & $04 \%$ & $06 \%$ & \\
\hline Very Good & $>21$ & $01 \%$ & $04 \%$ & \\
\hline
\end{tabular}

Table 2:- System wise comparison of pharmaco therapeutic knowledge among Interns \& MBBS students

\begin{tabular}{|l|l|l|l|}
\hline & Mean scores of MBBS & Mean scores of interns & P value \\
\hline CVS & $2.35 \pm 1.2$ & $4.53 \pm 1.3$ & 0.0001 \\
\hline Chemo & $3.5 \pm 1.23$ & $4.12 \pm 1.05$ & 0.0002 \\
\hline Analgesic & $2.41 \pm 0.93$ & $2.53 \pm 0.78$ & 0.36 \\
\hline Emergency & $1.97 \pm 0.7$ & $2.24 \pm 0.7$ & 0.01 \\
\hline
\end{tabular}

Fig 1:- Comparison Of Grades Of Mbbs Students And Interns

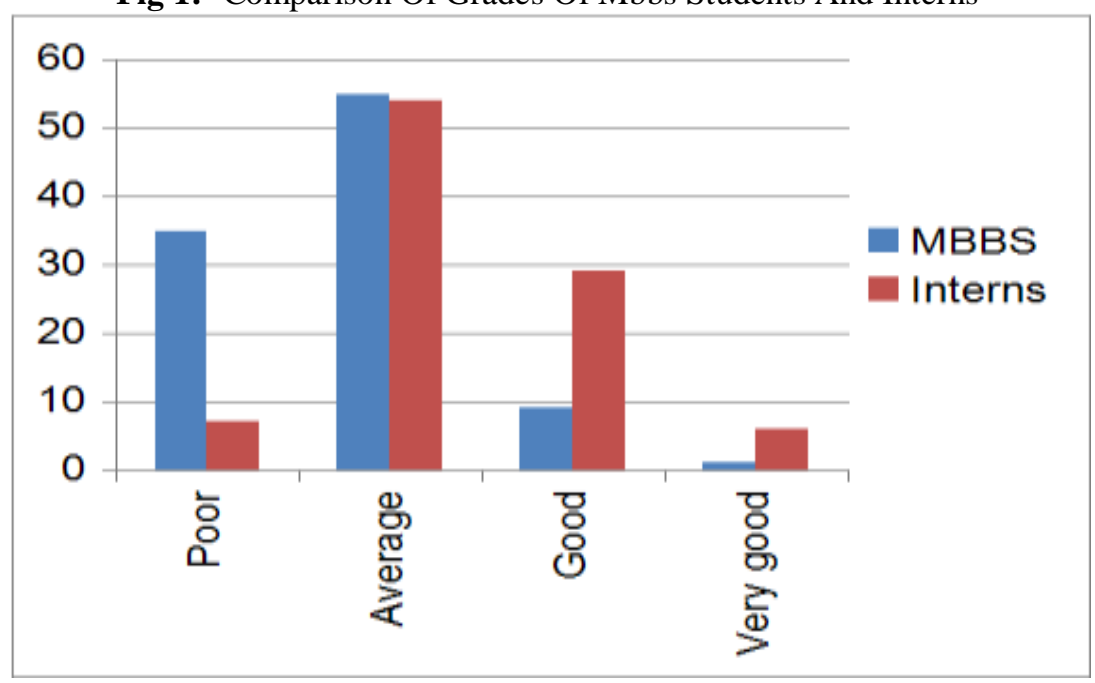

Fig 2:- Graphical Presentation Of Comparison Of Number Of Questions Attempted \&Unattempted Among Mbbs Students \& Interns

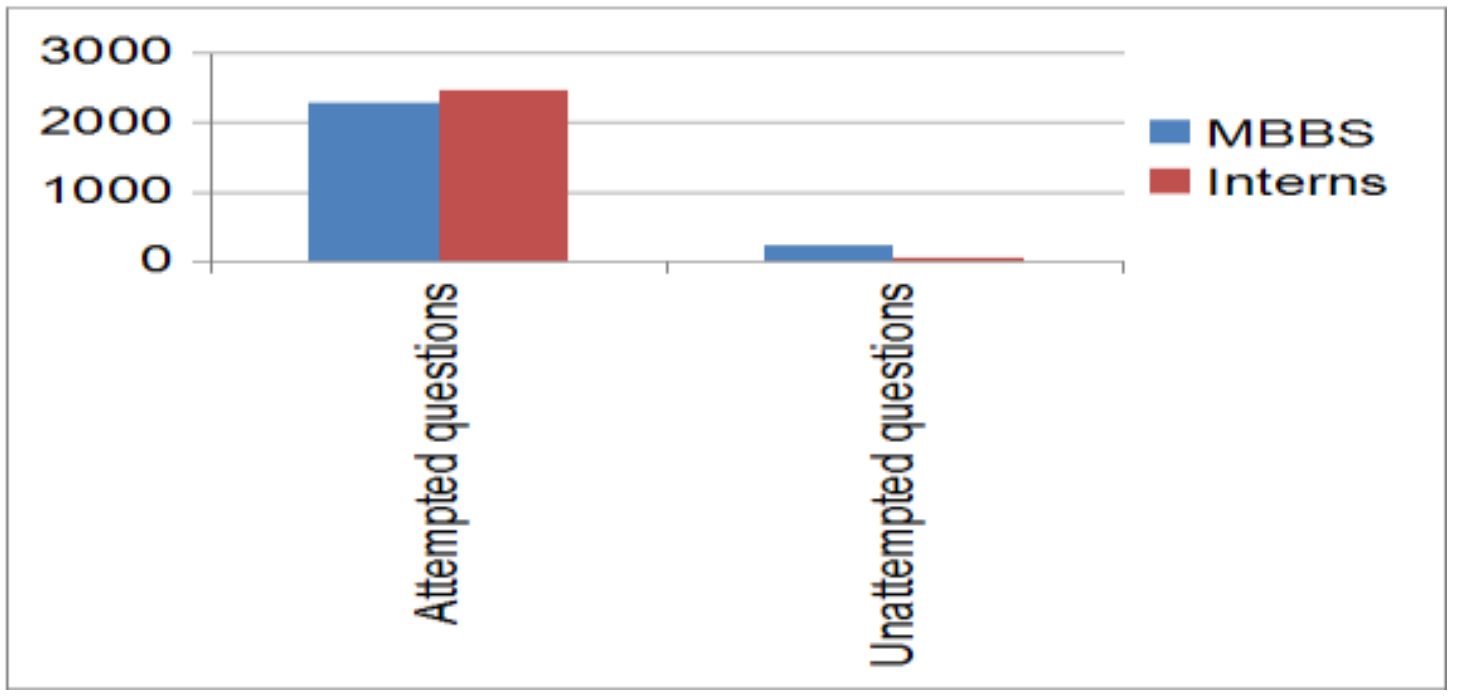


Figure 3:- System-wise comparison of mean scores of MBBS \& Interns students

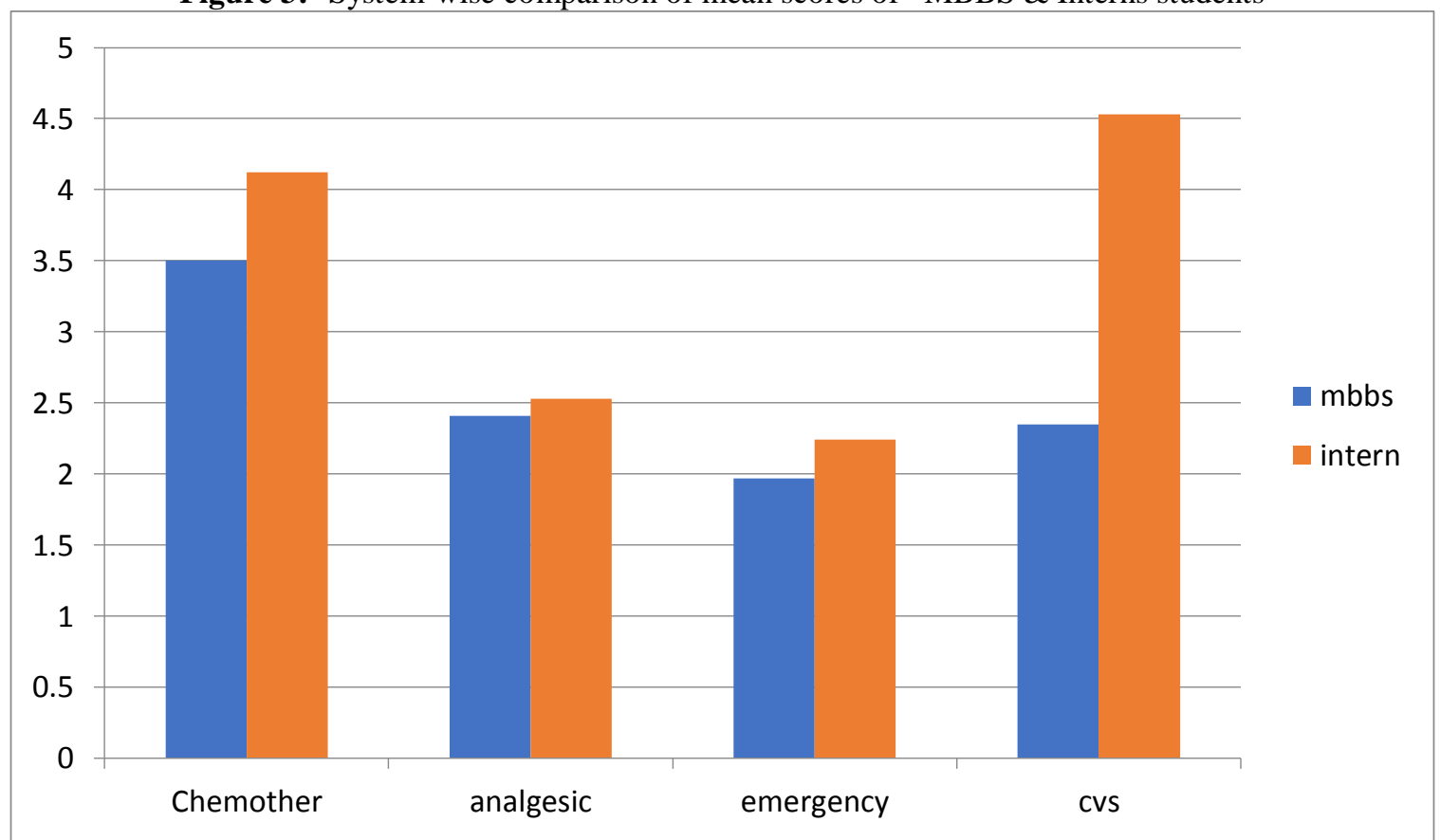

\section{Discussion:-}

The subject of pharmacology is a broad one and embraces the knowledge of the source, physical and chemical properties, compounding, physiological actions, absorption, fate along with excretion and therapeutic uses of drugs (9)

Pharmacology is one of the most important subjects for training students pursuing MBBS. It forms the backbone of medical practice. Apart from providing the therapeutic uses of drugs, it also provides a deep insight into their pharmacodynamics \& pharmacokinetic parameters ${ }^{(10)}$. The present study was designed to compare the knowledge of pharmacotherapy of $2^{\text {nd }}$ year MBBS undergraduates with that of Interns. Purpose of the study was also to find out whether exposure to clinical practice as Intern can help to enhance the knowledge of pharmacotherapeutics.

In this study, it was found that the overall performance of Interns was better than the undergraduates. 35\% MBBS undergraduates scored below 10 out of 25, while the figure was only $7 \%$ in Interns.

However, there was not much difference in the average score among the two groups with 55\% MBBS students and $54 \%$ of Interns scoring an average result. Most of the Interns found the questionnaire to be easy whereas MBBS students expressed their difficulty in solving the questions. $8.64 \%$ of the total questions were left unattempted by MBBS students whereas the figure was $1.84 \%$ among Interns. (Fig.2)

In questions pertaining to emergency conditions, majority of the Interns (85\%) responded correctly about the life saving drug adrenaline for the treatment of anaphylactic shock as compared to MBBS students (65\%). Another question regarding treatment of acute asthma was answered correctly by $70 \%$ of the interns, whereas only $40 \%$ MBBS students could answer the same question correctly. Similarly for carbamate poisoning the interns fared better (60\%) than MBBS students (43\%).

In questions regarding correct dosage, the therapeutic dose of aspirin for antiplatelet action as $75-150 \mathrm{mg}$ was known to $62 \%$ of the interns while only $40 \%$ of MBBS students could give the dose correctly. Similarly the daily dose of iron in iron deficiency anaemia is $200 \mathrm{mg}$ was known to $73 \%$ interns while $52 \%$ MBBS students could respond correctly. 
It was also observed that Interns had better knowledge in chemotherapy. Streptomycin was the only drug which could not be given orally in the treatment of tuberculosis was known to $81 \%$ interns as to 54\% MBBS students. First line drug for enteric fever is ceftriaxone was answered correctly by $80 \%$ interns as opposed to $52 \%$ MBBS students. ACE Inhibitors are used as anti-hypertensives but are contraindicted in pregnancy. $66 \%$ interns could identify this as compared to $35 \%$ MBBS students. Gross lack of knowledge was observed in relation to useful drugs in acute angina $(57 \%)$ and decompensated heart failure (30\%) among MBBS students, as compared to interns (76\%) and (58\%) respectively. $40 \%$ of interns knew about the latest Joint National Committee recommendations for treatment of hypertension as compared to only $25 \%$ MBBS students. That beta blockers are no longer first line drugs for hypertension ${ }^{(11)}$ was unknown to most of the students. Most common adverse drug reaction of statins is myalgia, $63 \%$ of interns were aware of this in comparison to $36 \%$ MBBS participants.

The only analgesic safe in dengue fever is paracetamol, was known to $87 \%$ interns and $65 \%$ MBBS students. Tramadol is a very common opioid analgesic, it was known to 63\% interns as opposed to 54\% MBBS participants.

In the present study, the overall pharmacotherapeutic knowledge of interns was found to be better than MBBS students and statistically significant difference was observed. The results of the present study revealed that students can perform in a better way, with improved scores when taught with the integrated approach. Similar results were shown in a study conducted by Kate et al.[12] Hence, the approach has to be clinically driven and patient focused so that the facts are imprinted in the minds of the students.

This is a single center study involving limited number of participants. Results may vary from one institution to the other. Results of this study cannot be extrapolated to other institutes. A Meta analysis of similar trials conducted in other medical institutes can give a better overview.

\section{Conclusion:-}

Nowadays medical profession has become intensely competitive and globalized. It is important that the graduates and post graduates from medical institutions are well equipped with adequate knowledge and clinical skills to face challenges anywhere in the world. For this, medical institutes need to bring about innovations in medical teaching and regularly monitor them through regulatory bodies ${ }^{(13)}$.

The World federation for Medical Education (WFME) has decided to form a policy to improve health system performance by promoting high quality medical education ${ }^{(14)}$. Its mission is to improve the quality of higher education by establishing accreditation standards for basic medical education ${ }^{(15)}$, post graduate medical education ${ }^{(16)}$ and continuing professional development of medical doctors ${ }^{(17)}$

The present study is providing us valuable information about the knowledge of pharmacotherapeutics among MBBS students and interns in a private medical college and that the interns have a better knowledge of clinical pharmacology and pharmacotherapeutics than the MBBS students. In one of the similar studies, comparison between two batches as well as between topics taught with integrated learning program versus traditional method showed that students performed better in the topics, taught with integrated approach. ${ }^{[18]}$

The traditional teaching is in the form of didactic lectures and bench work practicals. More emphasis could be laid on prescription writing and problem based learning to make the students competent enough in clinical practice. We conclude that gaining knowledge and simultaneously allowing students to put their knowledge into practice with real patients under appropriate supervision is essential for complex task of medical learning. This would substantially allow students to work in context and carry out learnt skills and prepare better for future practice.

\section{Acknowledgement:-}

We are thankful to our HOD Dr. S.C. Chopra for his valuable advice. We are also thankful to all the participants for their coorperation and patience. 


\section{References:-}

1. Chaurasia RC. Pharmacology exercise for undergraduate: MLNMC model. Int J Basic ClinPharmacol 2013; 2(4):495-497.

2. Mohan L, Chogtu B, Adiga S, et al. Undergraduate medical students' perceptions regarding personal drug selection exercise. International Journal of Pharmacology and Clinical Sciences 2012; 1(2):61-67.

3. Upadhyaya P, Seth V, Sharma M, et al. Prescribing knowledge in the light of undergraduate clinical pharmacology and therapeutics teaching in India: views of first-year post graduate students. Adv Med EducPract 2012;3: 47-53.

4. Tripathi KD. Introduction, routes of administration. In:Essentials of Medical Pharmacology. $7^{\text {th }}$ ed. New Delhi: Jaypee Brothers Medical Publisher; 2014. P. 2

5. Ahmed MW, Dass P, Gulabani M, et al.'Undergraduate MBBS and BDS students' Opinion Based Survey On Current Teaching Practices In Pharmacology and Changes Recommended for Betterment of the Same" Jn of evol of Med and Den Sci2014;Vol.3, Issue 70, Dec 15;14923-29.

6. Medical council of India regulation on graduate medical education. New Delhi: Medical Council of India; 1997.

7. NatuMV,Singh T. Objective structure practical examination (OSPE) on pharmacology- student's point of view. Indian J Pharmacol 1994;26:188-9.

8. Rao SG, Karanth S, KumarV,et al. A scheme of practical examination in pharmacology for evaluating skills involved in problem solving. Indian J Pharmacol 1992;24:145-6.

9. Rivera SM, Gilman AG. Drug invention and the pharmaceutical industry. In:The pharmacological basis of therapeutics, $12^{\text {th }}$ edn. New york: MCGraw-Hill Publishers;2012. p.3-16

10. Khan SA, Siddiqui NI. Pharmacotherapeutics knowledge of some nonemergency and emergency conditions among medical undergraduates in an Indian medical college. Ind J Pharacol 2016;48:252-7.

11. James PA, OparilS, Carter BL, Cushman WC, Dennison-Himmelfarb C, Handler J. 2014 Evidence based guideline for the management of high blood pressure in adults: Report from pael members appointed to the eighth joint national committee (JNC8).Dec 18 2013. JAMA 2013.

12. Kate MS, Kulkarni UJ, Supe A, Deshmukh YA. Introducing integrated teaching in undergraduate medical curriculum. Int J PharmaSci Res (IJPSR) 2010; 1:18-22.

13. Joshi MA. Quality assurance in medical education. Indian J Pharmacol 2012;44:285-287.

14. WFME. Available from: http://www.wfme.org/. (last cited 2011 Dec 20)

15. WFME Global Standards for Quality Improvement in Basic Medical Education BME in English.pdf. Available from: http://www.wfme.org/standards/bme. (Updated 2011Sep 13, Last cited 2011 Dec 20)

16. WFME Global Standards for Quality Improvement in Postgraduate Medical Education English.pdf. Available from http://www.wfme.org/standards/pgme. (Updated 2011Jul 14, Last cited 2011 Dec 20)

17. WFME Global Standards for Quality Improvement in Continuing Professional Developement CPD of Medical Doctors English.pdf. Available from http://www.wfme.org/standards/cpd. (Updated 2011Jul 14, Last cited 2011 Dec 20)

18. PankajBhardwaj, Nikha Bhardwaj, ${ }^{1}$ Farzana Mahdi, ${ }^{1} \mathrm{~J}$ P Srivastava, ${ }^{1}$ and Uma Gupta ${ }^{1}$ Integrated teaching program using case-based learningInt J Appl Basic Med Res. 2015 Aug; 5(Suppl 1): S24-S28. 